\title{
Green synthesis, characterization of biomaterial-supported zero-valent iron nanoparticles for contaminated water treatment
}

\author{
K. Sravanthi, D. Ayodhya and P. Yadgiri Swamy*
}

\begin{abstract}
Background: In this present work, we synthesized zero-valent iron nanoparticles (ZVIN) using reproducible Calotropis gigantea (CG) flower extract served as both reducing and stabilizing agent by completely green approach. ZVIN are widely used in contaminated water treatment and can be prepared by several different methods.

Method: Iron nanoparticles formed in this method are mainly ZVIN and were characterized by the various physicochemical techniques, viz, ultraviolet-visible absorption spectroscopy (UV-vis), Fourier transform-infrared spectroscopy (FT-IR), X-ray diffraction (XRD), scanning electron microscopy (SEM), and energy-dispersive X-ray spectroscopy (EDX).

Results: FT-IR and UV-vis absorption spectra reveal that the polyphenols present in the CG flower extract may be responsible for the reduction and stabilization of the ZVIN. SEM images show some agglomeration among the particles and the average size of the particles in the range of 50-90 nm. ZVIN tend to agglomerate, resulting in a significant loss of reactivity. To overcome this problem, we have synthesized ZVIN that are immobilized on biomaterial with the help of chitosan. This low-cost sorbent was used to remove organic pollutants from waste water.

Conclusions: Herein, we report the percentage of removal of methylene blue (MB) and aniline by synthesized sorbent from contaminated water. The adsorption isotherms of Langmuir and Freundlich models have been used to explain experimental equilibrium adsorption data. The adsorption of MB and aniline on sorbent follows pseudo-second order kinetics.
\end{abstract}

Keywords: Green synthesis, Zero-valent iron nanoparticles, Calotropis gigantea flower extract, Chitosan, Methylene blue, Aniline

\section{Background}

Nowadays, environmental pollution is the perilous problem of all over the world. Especially contamination of water originates from different paths and causes great damage to the biosphere (Wang et al. 2014a, b). Industrial effluents from textile, printing, glass, paint, food, ceramic, pharmaceutical, paper, polymers, etc. preponderantly contain organic waste such as synthetic dyes (Wanyonyi et al. 2014; Rebitanim et al. 2012). Trivial amounts of dye residues also bestow their characteristic color to the wastewater, which

\footnotetext{
* Correspondence: parikibandla@gmail.com

Department of Chemistry, University College of Science, Osmania University, Hyderabad, Telangana State 500007, India
}

leads the formation of dazzling contaminants. Moreover, an anaerobic degradation of azo dyes prevails in the production of carcinogenic and highly toxic amines. So there is a conclusive need of destruction of this hazardous waste from industrial effluents before disposal to the environment. Many kinds of chemical, physical, and biological processes have been developed for the remediation of water pollution, including microbial degradation, filtration, coagulation, membrane separation, and others. But all these methods involve some disadvantages and limitations like high cost and poor removal efficiency (Sttle et al. 2015). Earlier reports showed that a lot of research has been done on the photo-catalytic degradation of synthetic 
dyes. But in the dislodgement process of organic waste, adsorption is supposed to be preferable over photocatalytic degradation, which sometimes leads toxic intermediates.

Nanotechnology is an immortally patulous area with enormous applications in various fields including food, agriculture, medical, pharmaceutical, catalysis, optical, and pollution control in a broad way (Shukla and Iravani. 2017). In recent times, nanoscale zero-valent iron has received much attention from research areas like remediation of contaminated water and soil due to its high specific surface area, small particle size, and majestic reactivity of surface sites (Lanlan et al. 2014; Mikhak et al. 2017). Apart from that, zero-valent iron nanoparticles (ZVIN) follows the maximal tenets of green chemistry as a non-toxic, inexpensive, and environmentally compatible material (Li et al. 2006; Zhipan et al. 2014). If iron reacts with water, it forms a thin oxide layer known as goethite (FeOOH) and hydrogen gas (Li and Zhang 2006). Goethite has more affinity towards contaminates (Zhang et al. 2014). Thus zero-valent iron core and iron hydroxides have the shells which provide a characteristic core-shell structure to ZVIN with unique redox properties (Yan et al. 2012; Ritu et al. 2011). Because of attractive qualities like electron donating property during the oxidation of $\mathrm{Fe}^{2+}$ to $\mathrm{Fe}^{3+}$ and existence of various mineral forms of iron, the ZVIN have been found to be more important in the adsorption and removal of environmental pollutants (Chicgoua et al. 2012; Kumar et al. 2014). ZVIN are boon especially in alleviating contaminants such as dyes, organic pesticides, halogenated organic compounds, inorganic ions like nitrate, fluoride, and sulfate, viruses, nitro-aromatic compounds, $\mathrm{PCBs}$ and heavy metals such as $\mathrm{Pb}, \mathrm{As}, \mathrm{Cr}$, and $\mathrm{Cd}$ (Zheng et al. 2011) from polluted water. Carbonsupported ZVIN are also used in the removal of uranium from natural and synthetic water (Richard and Crane 2014).

Several physical and chemical production methods including mechanical milling (Karimi et al. 2014), sodium borohydride (Satapanajaru et al. 2008; Madhavi et al. 2014), ethylene glycol (Raveendran et al. 2003), solvothermal method (Basavaraju et al. 2011), and carbothermal synthesis (Allabaksh et al. 2010) have been employed for the preparation of ZVIN. But ZVIN, synthesized by above conventional methods, agglomerate rapidly in clusters due to Van der Waals and magnetic forces (Qiangu et al. 2013). Sometimes ZVIN undergo oxidation by oxidants like dissolved oxygen or water (He and Zhao 2005). Agglomeration and oxidation of ZVIN result in the formation of large particles and also reduce the delivery of ZVIN to the targeted contaminant places (Kim et al. 2008). Previously stable ZVIN are synthesized using biodegradable polymers or surfactants such as resin, starch, carboxymethyl cellulose (CMC), citric acid, and chitosan (Madhavi et al. 2013; Morales et al. 2013) as stabilizing or capping agents. Stabilizer molecules prevent attractive Vander Waals and magnetic forces by providing strong inter-particle electrostatic repulsions.

In recent years, ZVIN are widely prepared by plant extract-mediated liquid phase bio-reduction of ferrous or ferric salt solutions. The peculiarity of this liquid phase reduction is that it has been carried out at room temperature and generally completes within few minutes. Furthermore, it involves mixing of aqueous solutions of plant extract and ferric salt in which hazardous materials are neither used nor generated. In general, plant extracts comprised phenols, flavonoids, terpenoids, proteolytic enzymes, etc., which eventually act as reducing and capping agents in the production of ZVIN. Based on the notion of green chemistry, previously ZVIN are synthesized from extracts like tea leaves (Nadagouda et al. 2010), eucalyptus leaves (Wang et al. 2014a, b), vine leaves (Machado et al. 2013), Rosa damascene, Thymus vulgaris, and Urtica dioica (Mehdi et al. 2017). But the recent observations showed that the sorption and dispersion capacity of ZVIN increased by the support of porous materials like clays, resins, and carbon materials (Shu et al. 2010; Sunkara et al. 2010).

In this paper, we report the green synthesis of ZVIN using Calotropis gigantea (CG) flower extract as both reducing and stabilizing agent. In addition, a novel sorbent, which is the composite of as-synthesized ZVIN, biomaterial, and chitosan, was also prepared. Here, the biomaterial was prepared from Pithecellobium dulce seeds, which is used as a good supporting material to ZVIN in dispersion and sorption process (Arshadi et al. 2014). It is well known that chitosan is a second most abundant polysaccharide in the world and can be obtained from natural chitin which is a renewable, biodegradable and nontoxic polysaccharide. Some previous studies showed that chitosan increases removal capacity of biochar to remove heavy metals from contaminated water (Zhou et al. 2013). Here, the major role of chitosan is to attach fine ZVIN onto the biomaterial. According to the principles of green chemistry, here, we developed a new synthetic process for sorbent, which involves eco-friendly, inexpensive, non-hazardous, and renewable materials. The synthesized ZVIN and sorbent were characterized for UV-vis, FT-IR, XRD, SEM, and EDX. Here, we also discussed the effective adsorptive removal of organic waste such as methylene blue (synthetic dye) and aniline (aromatic primary amine) from contaminated water by the synthesized sorbent.

\section{Methods}

Ferric nitrate nonahydrate $\left(\mathrm{FeNO}_{3}, 9 \mathrm{H}_{2} \mathrm{O}\right)$, acetic acid, sodium hydroxide $(\mathrm{NaOH})$, chitosan $[\mathrm{MW} \approx 70,000$ and more than $80 \%$ deacetylated], ethyl alcohol, methylene blue, and aniline chemicals are all AR grade and purchased 
from Sigma Aldrich chemicals. The fresh flowers of Calotropis gigantea and Pithecellobium dulce seeds were collected and used for the preparation of ZVIN.

\section{Collection of extract and biomaterial}

Calotropis gigantea flowers were washed properly and were then cut into small pieces. These finely cut pieces were grind, and $10 \mathrm{mg}$ weight of flowers was mixed with $100 \mathrm{~mL}$ double-distilled water. It was boiled for $5 \mathrm{~min}$. After cooling, the solution was filtered thrice by Whatman no.1 filter paper to get clear extract. Dry Pithecellobium dulce seeds were collected and washed with distilled water and were put in the oven for $48 \mathrm{~h}$ at $70{ }^{\circ} \mathrm{C}$. After cooling, the biomaterial was finely ground, washed with doubledistilled water, and oven dried at $65^{\circ} \mathrm{C}$.

\section{Preparation of ZVIN}

$0.01 \mathrm{M} \mathrm{FeNO}_{3} .9 \mathrm{H}_{2} \mathrm{O}$ was prepared in double distilled water and was mixed with flower extract in 1:1 ratio. For the reduction of $\mathrm{Fe}^{+3}$ ions, equal volume of flower extract was added slowly to aqueous ferric nitrate solution with constant stirring for $15 \mathrm{~min}$ on a magnetic stirrer and the reaction was carried out at room temperature. Here, the Calotropis gigantea flower extract used as both reducing and stabilizing agent. The formation of iron nanoparticles were indicated by the color change of solution from light pink to black. The black precipitate was washed several times with 1:1 ethanol and water and then with double distilled water. The obtained nanoparticles were dried at $60{ }^{\circ} \mathrm{C}$ in the oven.

\section{Preparation of sorbent}

A composite sample was prepared by dissolving chitosan powder first in a $100 \mathrm{~mL}$ of $2 \%$ acetic acid solution and then synthesized ZVIN were dispersed in the chitosan solution. To the above mixture, biomaterial was added and stirred for $60 \mathrm{~min}$ to form a homogeneous mixture. This mixture was added drop-wise into a $500 \mathrm{~mL}$ of $1.5 \% \mathrm{NaOH}$ solution and kept undisturbed for $15 \mathrm{~h}$ at room temperature. The solid products were then separated by decantation method and washed with deionized water to remove the excess $\mathrm{NaOH}$ and oven dried for $24 \mathrm{~h}$ at $70{ }^{\circ} \mathrm{C}$. Here the ratio of chitosan, biomaterial, and ZVIN particles in the sorbent were 1:1:0.5, 1:1:1, and 1:1:2. For comparison, another sorbent in the 1:1 ratio of biomaterial and chitosan was also synthesized without addition of ZVIN.

\section{Characterization of ZVIN and sorbent}

UV-vis absorption analysis was carried out using UV-3600 spectrophotometer in the range of 200-800 nm. Scanning electron microscope (SEM) imaging analysis of the samples was conducted using a Zeiss evo 18 instrument. The sample crystallinity was examined using X-ray diffraction (XRD) analysis with a computer-controlled Xray diffractometer (X'pert pro diffractometer) and equipped with a stepping motor and graphite crystal monochromator. The FT-IR spectra were analyzed by Shimadzu spectrophotometer with $\mathrm{KBr}$ pellet.

\section{Batch experiments of decolorization of methylene blue}

Decolorization of $\mathrm{MB}$ experiments was carried out at room temperature and at its original $\mathrm{pH}$. In this study, $400 \mathrm{mg}$ of sorbent material was mixed with $500 \mathrm{~mL}$ of different concentrations (50-400 ppm) of MB solutions. The mixture was stirred for certain period of time $(5,10$, $15,20,25,30,40,50,60,90,120,180,240,300$, and $360 \mathrm{~min}$ ), using a magnetic stirrer to find out the effect of contact time in the removal of MB. During the adsorption process, about $4 \mathrm{~mL}$ of aliquot samples was withdrawn from the reaction mixture by syringe at certain time intervals and the sorbent was removed using $0.45-\mu \mathrm{m}$ filters. Concentration of $\mathrm{MB}$, remained in solution, was determined spectrophotometrically by measuring absorbance at $665 \mathrm{~nm}$. The change in the concentration of $\mathrm{MB}$ was calculated from the difference between the initial and final equilibrium concentrations of $\mathrm{MB}$, and sorption efficiency or removal efficiency of the sorbent was computed from the following equation:

$$
\% \text { of removal }=\frac{\left(c_{0}-c_{\mathrm{e}}\right)}{c_{0}} \times 100
$$

where $c_{0}$ and $c_{\mathrm{e}}$ are total dissolved and equilibrium liquid phase concentrations $\left(\mathrm{mg} \mathrm{L}^{-1}\right)$, respectively. For comparative study, the above batch experiments were carried out with adsorbents, viz, synthesized ZVIN, blank, sorbent (1:1:0.5), sorbent (1:1:1), and sorbent (1:1:2) individually at identical reaction conditions.

\section{Batch experiments of aniline removal}

The aniline removal experiments were carried out with the initial concentration of aniline between 50 and $400 \mathrm{ppm}$ in distilled water. In this study, the amount of sorbent added to the aniline solution was $1 \mathrm{~g} \mathrm{~L}^{-1}$. The conditions such as neutral $\mathrm{pH}$ and $30{ }^{\circ} \mathrm{C}$ temperature were maintained throughout the experiment. Proper care was taken against auto-degradation, photodegradation, and degradation by $\mathrm{OH}$ radical. In this typical removal process, the solution was kept shaking at $300 \mathrm{rpm}$ and the amount of aniline removed determined at certain time intervals such as $30,60,120,180$, and 360 min to know the effect of contact time. At these time intervals, about $4 \mathrm{~mL}$ of liquid sample was withdrawn by syringe and filtered off using $0.45-\mu \mathrm{m}$ filters. The concentration of aniline, remained in solution, was determined spectrophotometrically by measuring absorbance at $232 \mathrm{~nm}$. The change in amount of aniline was calculated from 
the difference between the initial and final equilibrium concentrations of aniline. The sorption efficiency or removal efficiency of the sorbent was determined same as that of $\mathrm{MB}$ and also the experiment was repeated with each of the sorbent material, blank, and synthesized ZVIN. The amount of adsorbate adsorbed on the surface of sorbent at equilibrium $\left(q_{\mathrm{e}}\right)$ was calculated as:

$$
q_{\mathrm{e}}=\frac{\left(c_{0}-c_{\mathrm{e}}\right) v}{m q_{\mathrm{e}}}
$$

where $v$ (in liter) is the volume of the solution and $m$ (in gram) is the amount of adsorbent.

\section{Results and discussion}

\section{UV-vis absorption analysis}

UV-vis spectral scanning procedure was carried out from 200 to $800 \mathrm{~nm}$ to determine the formation of ZVIN (Fig. 1). Initially, the flower extract had pale pink color and showed higher absorption from 300 to $350 \mathrm{~nm}$. It indicates that the flower extract had free phytochemicals like carbohydrates, amino acids, and lipids. After the addition of flower extract to ferric solution, a black-colored colloidal solution was formed. The spectra of the blackcolored colloidal solution show the disappearance of strong absorption peaks at the region 300 to $350 \mathrm{~nm}$ and emerge broad absorption at higher wavelengths, suggesting the formation of polydispersed ZVIN. During the synthesis of ZVIN, the reduction of $\mathrm{Fe}^{+3}$ ions to $\mathrm{Fe}^{0}$ is indicated by the change in color due to excitation of electrons. Upon the whole, the formation of noble nanoparticles like silver and gold are indicated by characteristic UV-vis absorption pattern attributed to the surface plasmon resonance (SPM). But with few exceptions, such characteristic UV-vis peaks are not observed for ZVIN due to the high reactivity of iron, when compared to silver and gold. However, the decrease in the intensity of phytochemicals characteristic peak specifies the significance of flower extract in the synthesis of ZVIN.

\section{FT-IR analysis}

FT-IR technique provides information about interactions among biomolecules of CG flower extract and metal ions responsible for the formation and stabilization of iron nanoparticles. Figure 2a shows the spectrum of the CG flower extract and the colloidal solution of ZVIN stabilized in flower extract. By the deep observation of FT-IR spectrum, it was noticed that, when moving from CG flower extract to colloidal solution of ZVIN, the peak positioned at $3359 \mathrm{~cm}^{-1}$ (-OH and $-\mathrm{NH}$ stretching vibrations) was found to be shifted to $3361 \mathrm{~cm}^{-1}$ and also peak at $1641 \mathrm{~cm}^{-1}$ (amide) was shifted to $1642 \mathrm{~cm}^{-1}$ with increasing intensity. Similarly peaks at $1239 \mathrm{~cm}^{-1}$ (amide), $1083 \mathrm{~cm}^{-1}$ (-OH bending and $\mathrm{C}-\mathrm{O}-\mathrm{C}$ stretching), $976 \mathrm{~cm}^{-1}$, and $923 \mathrm{~cm}^{-1}$ of flower extract were shifted to $1231,1081,977$, and $922 \mathrm{~cm}^{-1}$ in colloidal solution of ZVIN respectively. Another two bands observed at $873 \mathrm{~cm}^{-1}$ (amine) and $680 \mathrm{~cm}^{-1}$ (aromatic alkanes) in the spectrum of CG flower extract. There was a complete absence of peaks at 873 and $680 \mathrm{~cm}^{-1}$ in FT-IR spectra of ZVIN colloidal solution. The highest peaks present at $3359-3361 \mathrm{~cm}^{-1}$ correspond to polyphenols, indicates the more abundance and prominent of phenolic functional groups for the reduction of $\mathrm{Fe}^{+3}$ to $\mathrm{Fe}^{0}$. Besides that,

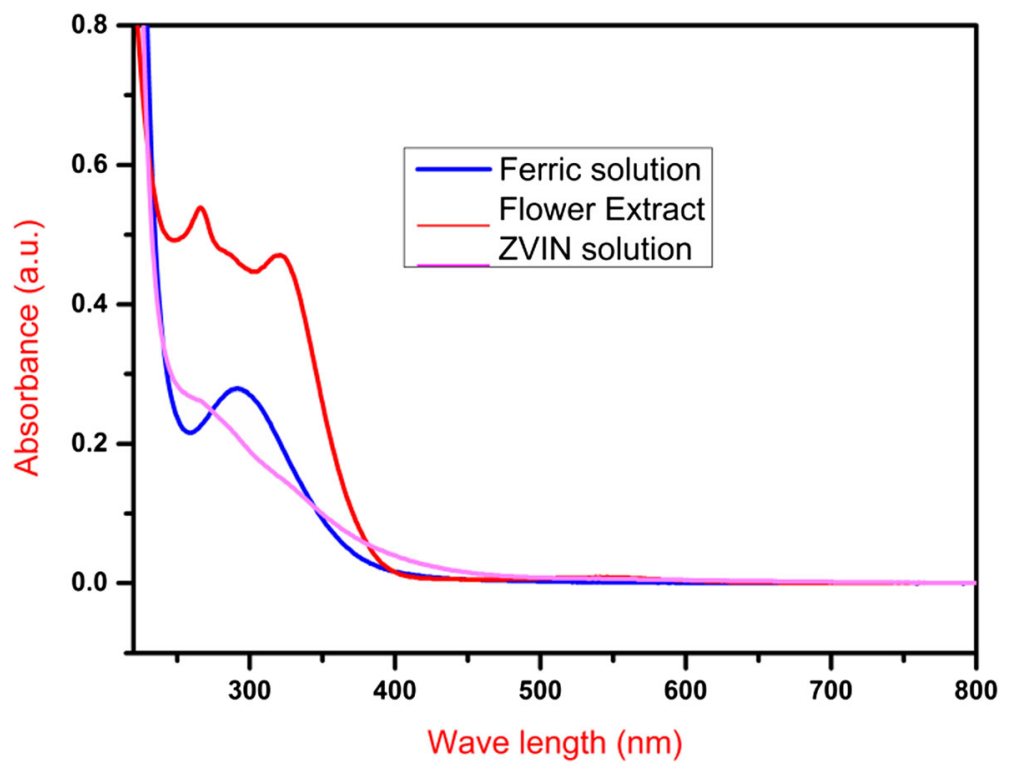

Fig. 1 The UV-vis absorption spectra of flower extract, ferric solution, and ZVIN solution 

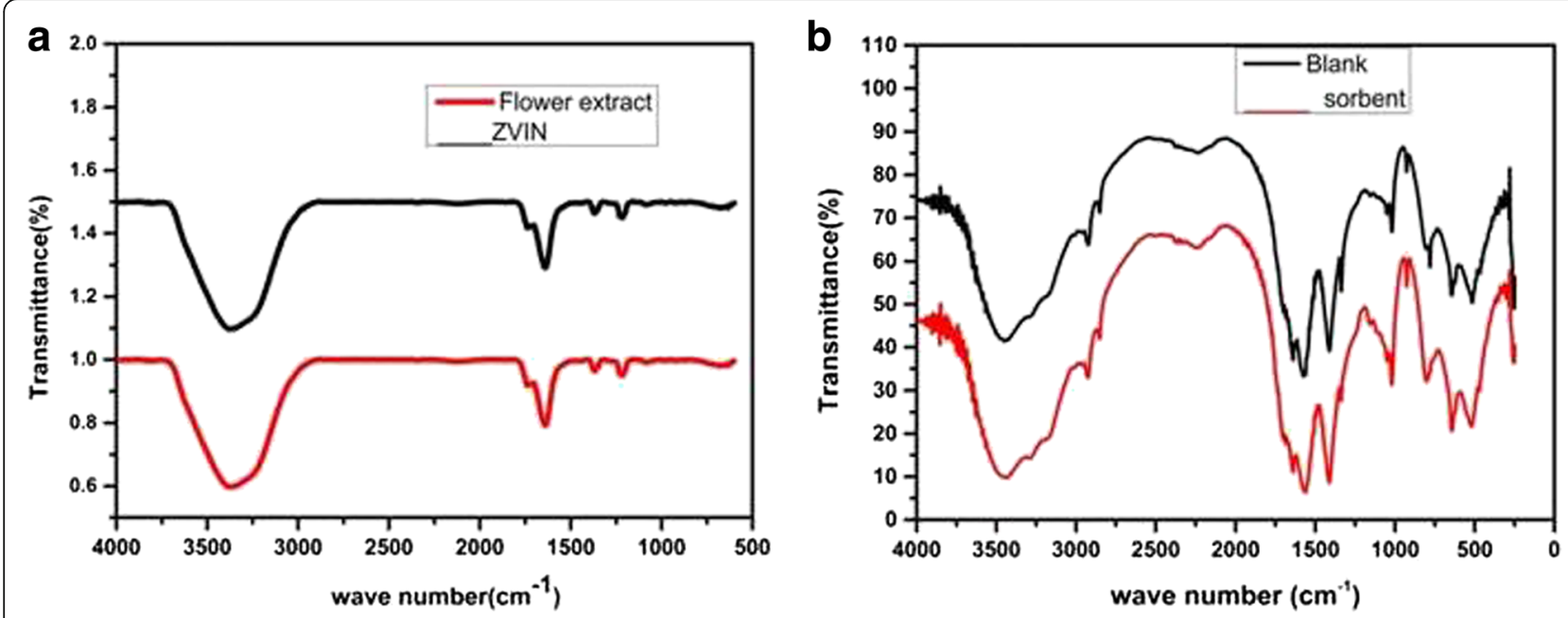

Fig. 2 The FT-IR spectra of a ZVIN and flower extract and $\mathbf{b}$ blank and sorbent

the more available phenolic groups provide the favorable molecular arrangement for the delocalization of unpaired electrons. So the flower extract enthralled the property of effective scavenging of free radicals. On the other hand, anti-oxidant capacity and anti-radical property increases with the number of phenolic hydroxyl groups. The appearance of a peak at $3359 \mathrm{~cm}^{-1}$ and shifting to $3361 \mathrm{~cm}^{-1}$ suggest that the phenolic or amine groups present in flower extract may be involved in ZVIN formation. The earlier reports (Mystrioti et al. 2015) indicate polyphenols were responsible for the reduction of Fe. From the spectrum, we can conclude that polyphenols present in the flower extract were responsible for reduction and stabilization of ZVIN which also agrees with UV-vis analysis.

FT-IR analysis of sorbent without ZVIN and with ZVIN also carried out to find out the effect of immobilization of ZVIN on the chemical composition of biomaterial. The spectrum (Fig. 2b) reveals the presence of $-\mathrm{OH}$ and $-\mathrm{NH}$ stretching vibrations $\left(3432 \mathrm{~cm}^{-1}\right),-\mathrm{CH}_{2}$ and $-\mathrm{CH}_{3}$ symmetric and asymmetric stretching vibrations $\left(2924 \mathrm{~cm}^{-1}\right.$, $\left.2853 \mathrm{~cm}^{-1}\right)$, amides $\left(1641 \mathrm{~cm}^{-1}, 1570 \mathrm{~cm}^{-1}\right)$, and $\mathrm{C}-\mathrm{O}$ stretching vibrations in carboxylate ion $\left(1414 \mathrm{~cm}^{-1}\right)$ in both the sorbent without ZVIN and also in the sorbent with ZVIN. By the addition of ZVIN to the biomaterial, there was no observable change in the basic chemical nature of the biomaterial. These results reveal that the proteins (amide peak) may be responsible for the immobilization of iron nanoparticles.

\section{XRD analysis}

The XRD technique was used to determine the material and crystalline structure of iron nanoparticles. The XRD analysis of ZVIN is shown in Fig. 3. The peaks at $2 \theta$ of $45^{\circ}$ and $65^{\circ}$ indicate that the presence of zero-valent iron predominantly in the sample and the diffraction peak at $2 \theta$ of $35.6^{\circ}$ indicates the presence of $\mathrm{Fe}_{2} \mathrm{O}_{3}$ (Khasim et al. 2011). Along with prominent diffraction peaks of iron nanoparticles, which demonstrate the crystallinity of ZVIN, here also exist some low-intensity peaks in between the $2 \theta$ value of $20^{\circ}-25^{\circ}$ corresponding to the organic matter coated on the surface of ZVIN (Fazlzadeh et al. 2017). These results show that the CG flower extract is successfully used for the synthesis and stabilization of ZVIN which can be reconciled by FT-IR analysis. Size of ZVIN is calculated from Sherrer's formula, given below, using peak broadening profile of peak at a $2 \theta$ value of $45^{\circ}$.

$$
d=\frac{0.94 \lambda}{\beta \cos \theta}
$$

where $\lambda$ is the wavelength (1.5418 $\AA$ ) and $\beta$ is the fullwidth at half maximum (FWHM) of corresponding peak. The size of synthesized ZVIN calculated from Sherrer's equation was $30 \mathrm{~nm}$. XRD patterns of both sorbent and blank (Fig. 3) are compared to know the surface modification of sorbent. In the XRD pattern of sorbent (1:1:2), diffraction peak at a $2 \theta$ value of $45^{\circ}$ indicates that nanoparticles contain mostly zero-valent iron which was mainly present on the surface of sorbent. However, by this analysis, it was clear that biomaterial and chitosan were good supporting materials to ZVIN for the preparation of a post grafting composite material due to prevention of oxidation.

\section{SEM and EDX analysis}

The SEM analysis was carried out to investigate the shape, crystal growth, and approximate size of ZVIN 


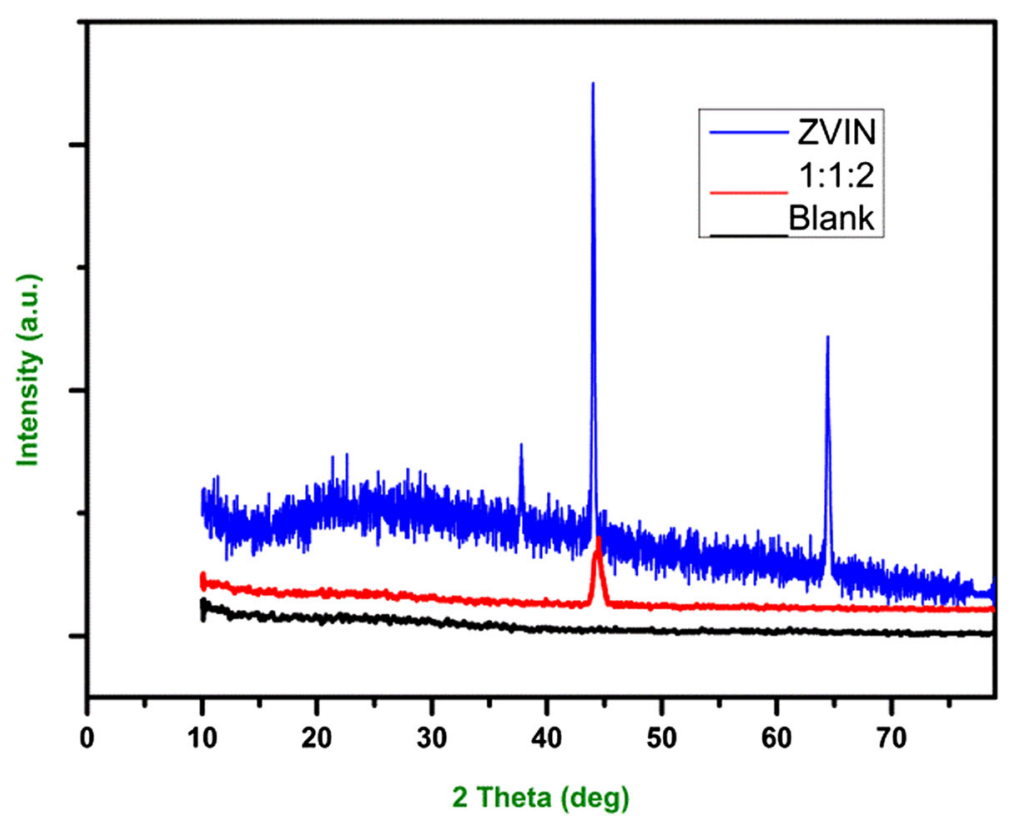

Fig. 3 The powder XRD pattern of ZVIN, sorbent, and blank

synthesized using CG flower extract. The SEM micrograph of synthesized ZVIN is shown in Fig. 4a, and it reveals that the ZVIN are spherical in shape and polydispersed with different sizes ranging from 50 to $90 \mathrm{~nm}$. These results show that the importance of CG flower extract in the synthesis of ZVIN but the synthesized ZVIN exhibit some agglomeration which was indicated by spherical shape and also non-uniform particle size with different void space. Hence, ZVIN are dispersed on the surface of the biomaterial to minify the aggregation. To know the surface morphology,
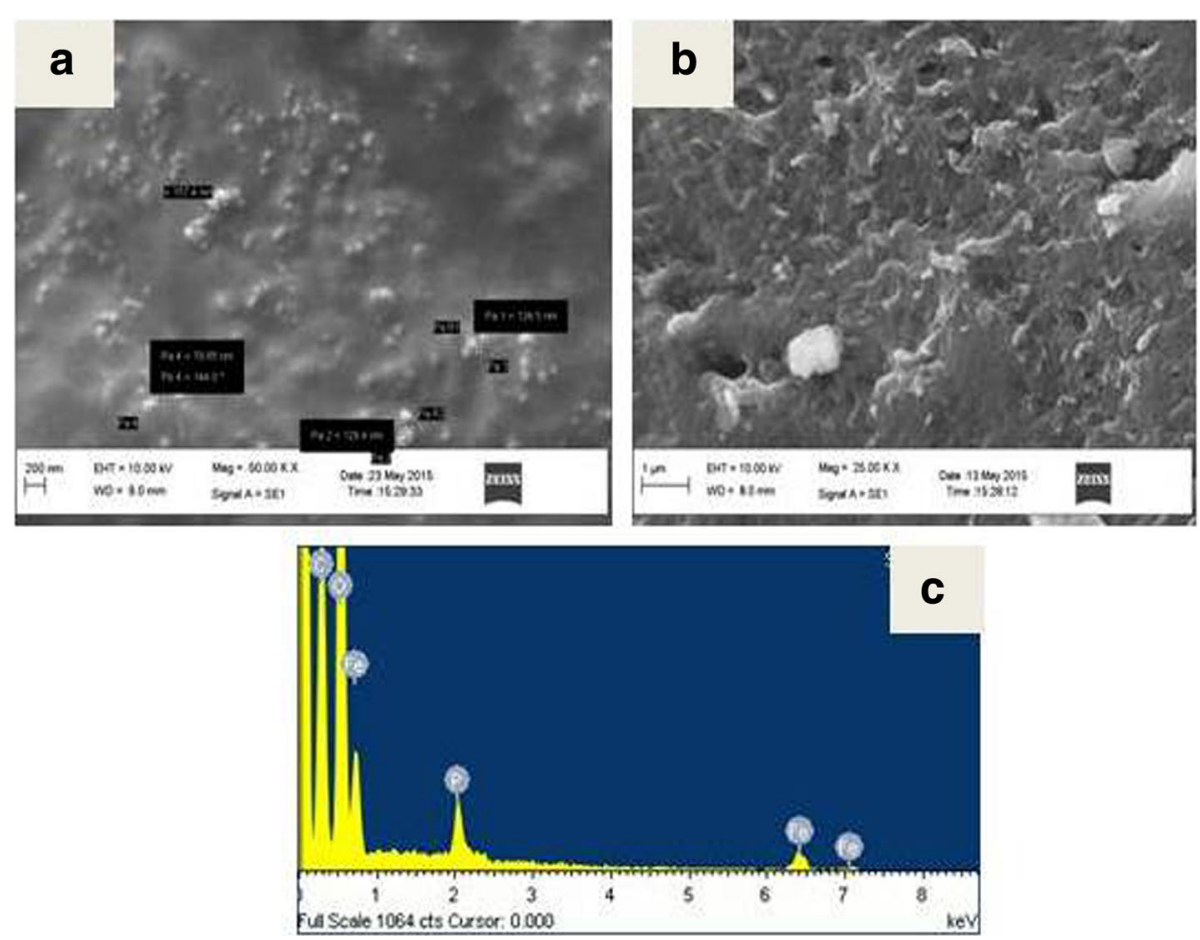

Fig. 4 SEM image of a ZVIN, b sorbent, and c EDX image of ZVIN 
the sorbent was characterized by SEM and shown in Fig. 4b. It shows that the surface was smooth with many gorges and ZVIN are well dispersed on the surface of the sorbent. EDX analysis gives the elemental status of synthesized ZVIN using flower extract (Fig. 4c) and revealed the proportion of iron, carbon, and oxygen atoms which were summarized in Table 1. It can also provide qualitative as well as quantitative information about elements that may be involved in the formation of nanoparticles. In the EDX spectrum of ZVIN, the highest peak due to absorption of elemental iron indicates the presence of iron nanoparticles and another peaks corresponding to carbon and oxygen atoms reveal the vital role of organic molecules from flower extract in the stabilization of ZVIN.

\section{Batch experiments of methylene blue decolorization and aniline removal}

Concentrations of $\mathrm{MB}$ and aniline remained in solution were determined spectrophotometrically by measuring absorbance at 665 and $232 \mathrm{~nm}$ respectively. Figure 5a, b shows the effect of contact time on MB decolorization and aniline removal, respectively, and reveal that all the adsorbent samples (blank, synthesized ZVIN, and sorbent material) showed some $\mathrm{MB}$ and aniline removal capacity. Among all the samples, the sorbent material (1:1:2) was found to remove the highest amount whereas lowest amount was removed by blank sample. Percentage of $\mathrm{MB}$ removal rates of blank, synthesized ZVIN, and sorbent materials (with different ratios of biomaterial, chitosan, and ZVIN) were 29.4\%, 63.1\%, 80.5\% (1:1:0.5), 83.9\% $(1: 1: 1)$, and $85.5 \%(1: 1: 2)$ respectively within the first $30 \mathrm{~min}$ (Fig. 5c). Percentage of aniline removal rates of blank, synthesized ZVIN, and sorbent materials were $17.1 \%, 49.4 \%, 56.3 \%(1: 1: 0.5), 59.1 \%(1: 1: 1)$, and $74.8 \%$ $(1: 1: 2)$ respectively after $12 \mathrm{~h}$ (Fig. $5 \mathrm{~d}$ ). These results showed that $\mathrm{MB}$ and aniline removal capacity of synthesized ZVIN enhanced in modified form.

\section{Adsorption isotherms}

To understand the mechanism of adsorption of MB and aniline on sorbent (1:1:2), Langmuir and Freundlich adsorption models were applied to experimental data.

Table 1 The elemental compositions and weight percentages of ZVIN

\begin{tabular}{lll}
\hline Element & Weight \% & Atomic \% \\
\hline C K & 29.77 & 45.48 \\
O K & 37.62 & 43.14 \\
P K & 2.49 & 1.48 \\
Fe L & 30.11 & 9.89 \\
Totals & 100.00 & 100.00 \\
\hline
\end{tabular}

\section{Langmuir model}

It was limited to adsorption on homogeneous surface by monolayer formation, with decrease in intermolecular forces among adsorbed molecules and also uniform energies of adsorption with no transmigration of adsorbed molecules (Dey et al. 2015; Eastoe and Dalton 2000). In addition, it is used to determine the maximum adsorption capacity of sorbent. The expression of Langmuir which relates molecules covered on solid surface to equilibrium concentration of liquid phase above the surface of sorbent is given by the following equation:

$$
q_{\mathrm{e}}=\frac{X_{\mathrm{m}} b c_{\mathrm{e}}}{1+b c_{\mathrm{e}}}
$$

where $q_{\mathrm{e}}\left(\mathrm{mg} \mathrm{g}^{-1}\right)$ and $c_{\mathrm{e}}\left(\mathrm{mg} \mathrm{L}^{-1}\right)$ are the amount adsorbed on the surface of unit mass of sorbent and the concentration of adsorbate in the solution at equilibrium respectively. $X_{\mathrm{m}}\left(\mathrm{mg} \mathrm{g}^{-1}\right)$ is the maximal adsorption capacity, and $b\left(\mathrm{~L} \mathrm{mg}^{-1}\right)$ is the empirical constant which gives the affinity of binding sites. The Langmuir expression can be given in the linearized form:

$$
\frac{1}{q_{\mathrm{e}}}=\frac{1}{X_{\mathrm{m}} b c_{\mathrm{e}}}+\frac{1}{X_{\mathrm{m}}}
$$

The linear plots of $1 / q_{\mathrm{e}}$ against $1 / c_{\mathrm{e}}$ show the Langmuir adsorption isotherms of $\mathrm{MB}$ and aniline on the surface of synthesized sorbent (1:1:2) (Fig. 6a, b). The values of parameters $X_{\mathrm{m}}$ and $b$ were calculated from slope and intercept of the straight line. The separation factor $R_{\mathrm{L}}$ (dimensionless quantity) provides basic information about essential features of Langmuir adsorption isotherm. If $0<$ $R_{\mathrm{L}}<1$, it is considered as favorable adsorption; if $R_{\mathrm{L}}>1$, it is considered as unfavorable adsorption; if $R_{\mathrm{L}}=0$, it is considered as irreversible adsorption; if $R_{\mathrm{L}}=1$, it is considered as linear adsorption (Zheng et al. 2008). The equation for $R_{\mathrm{L}}$ is:

$$
R_{\mathrm{L}}=\frac{1}{1+b c_{0}}
$$

where $b(\mathrm{~L} / \mathrm{mg})$ is Langmuir constant and $c_{\mathrm{o}}(\mathrm{mg} / \mathrm{L})$ is the initial concentration of adsorbate. The calculated Langmuir adsorption parameters are tabulated in Table 2. $R_{\mathrm{L}}$ values indicate the favorable adsorption of $\mathrm{MB}$ and aniline on synthesized sorbent $(1: 1: 2)$. Based on the value of correlation coefficient $\left(R^{2}\right)$, it was clear that the Langmuir model was well fitted to experimental data.

\section{Freundlich model}

Freundlich model assumes that adsorptions occur at heterogeneous binding sites and formation of multilayer takes place due to interactions among adsorbed molecules 

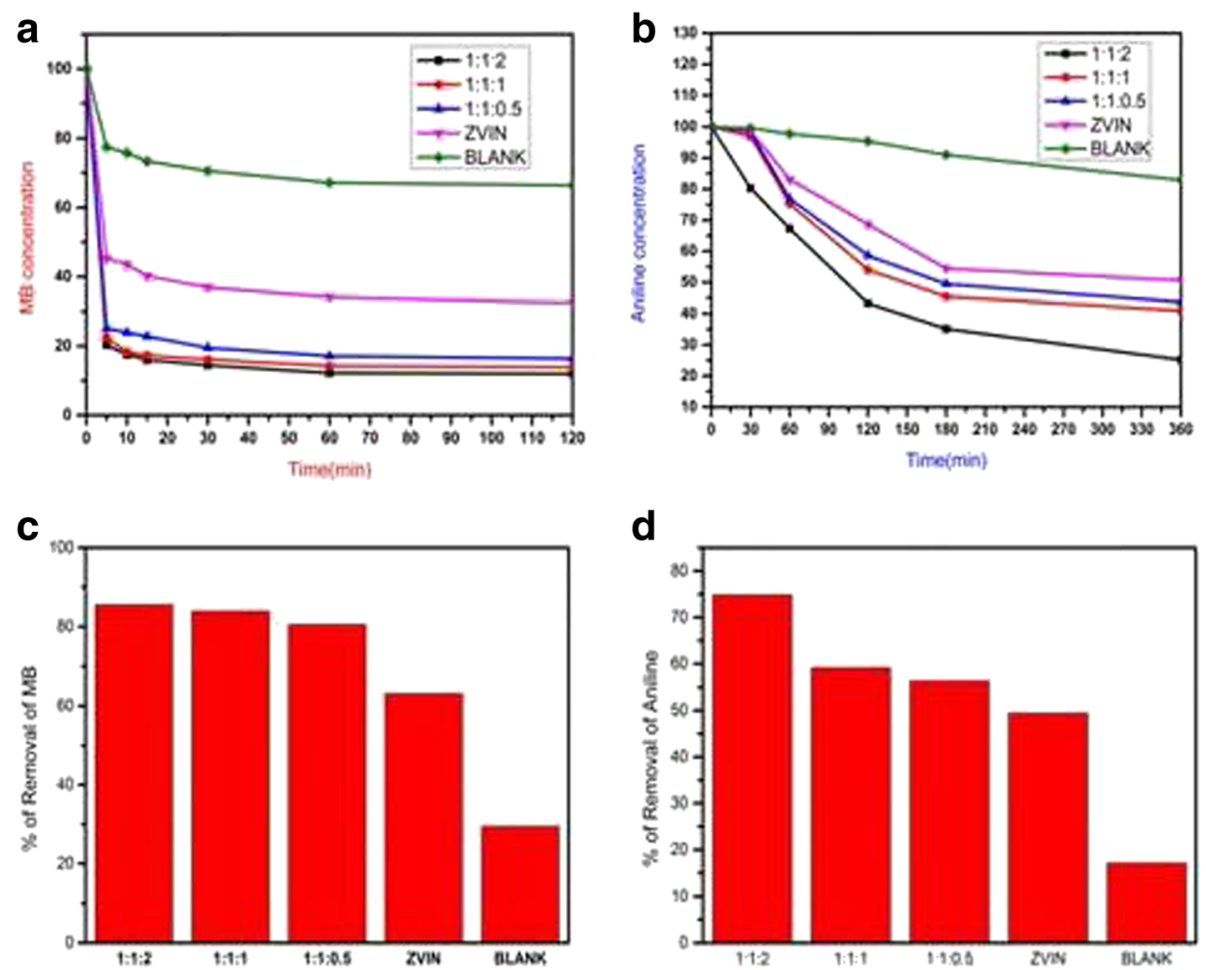

Fig. 5 Effect of contact time on percentages of concentrations (a) MB and (b) aniline and removal of percentage of (c) MB and (d) aniline as a function of composition of material
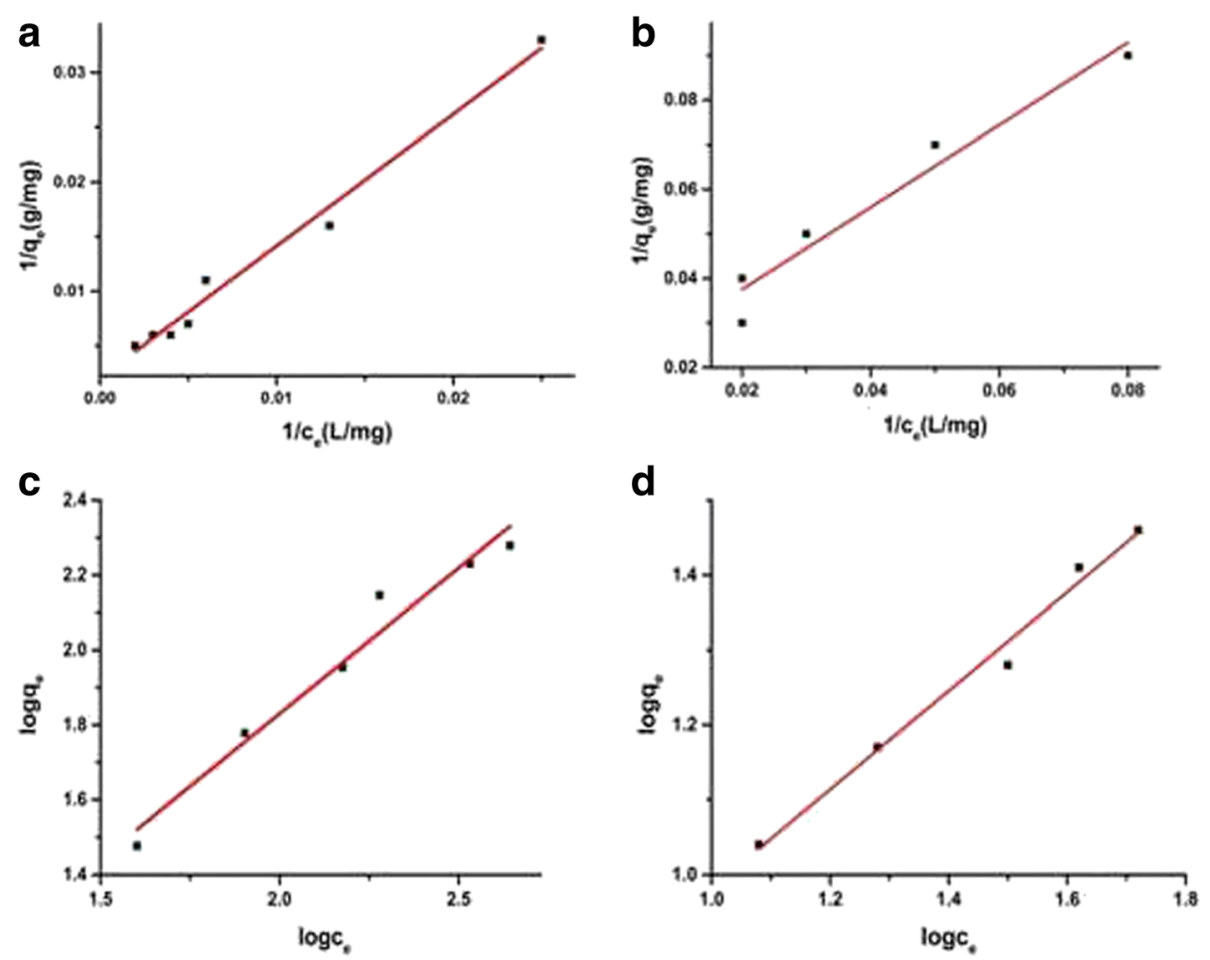

Fig. $6(\mathbf{a}, \mathbf{b})$ Langmuir adsorption isotherms and (c, d) Freundlich adsorption isotherms for MB and aniline removal 
Table 2 Langmuir and Freundlich parameters

\begin{tabular}{|c|c|c|c|c|c|c|}
\hline Isotherms & $X_{\mathrm{m}}(\mathrm{mg} / \mathrm{g})$ & $b(\mathrm{~L} / \mathrm{mg})$ & $K_{\mathrm{f}}\left(\mathrm{mg} \mathrm{g}^{1}(\mathrm{~L} / \mathrm{mg})^{1 /}\right)$ & $n$ & $R_{\mathrm{L}}$ & $R^{2}$ \\
\hline \multicolumn{7}{|l|}{ Langmuir } \\
\hline i. $M B$ & 500 & $1.7 \times 10^{-3}$ & - & & 0.59 & 0.98 \\
\hline ii. aniline & 52.63 & 0.0205 & - & & 0.33 & 0.93 \\
\hline \multicolumn{7}{|l|}{ Freundlich } \\
\hline i. $M B$ & & & 1.88 & 1.29 & & 0.95 \\
\hline ii. aniline & & & 2.09 & 1.5 & & 0.98 \\
\hline
\end{tabular}

on the surface of adsorbent (Soon et al. 2016). The expression for Freundlich adsorption isotherm is as follows:

$$
q_{\mathrm{e}}=K_{\mathrm{f}} c_{\mathrm{e}}^{1 / n}
$$

where $q_{\mathrm{e}}\left(\mathrm{mg} \mathrm{g}^{-1}\right)$ and $c_{\mathrm{e}}\left(\mathrm{mg} \mathrm{L}^{-1}\right)$ are the amounts adsorbed on the surface of unit mass of sorbent and the concentration of adsorbate in the solution at equilibrium respectively. $K_{\mathrm{f}}\left(\mathrm{mg} \mathrm{g}^{-1}\left(\mathrm{~L} \mathrm{mg}^{-1}\right)^{1 / n}\right)$ and $n$ are Freundlich constants which indicate sorption capacity and favorability of adsorption respectively. Here, $n$ value gives information about heterogeneity of binding sites, magnitude of driving force of adsorption. The values of $n$ between 1 and 10 $(1<n<10)$ indicate favorable adsorption (Vazquez et al. 2007). To calculate the values of Freundlich constants ( $K_{\mathrm{f}}$ and $n$ ), the equation of linear form of Freundlich isotherm was taken as follows:

$$
\log q_{\mathrm{e}}=\log K_{\mathrm{f}}+\frac{1}{n} \log c_{\mathrm{e}}
$$

The linear plots of $\log q_{\mathrm{e}}$ against $\log c_{\mathrm{e}}$ show the Freundlich adsorption isotherms of $\mathrm{MB}$ and aniline on the surface of synthesized sorbent (1:1:2) in Fig. 6c, d. Freundlich constants $K_{\mathrm{f}}$ and $n$ were calculated from slope and intercept values of the straight line and all the parameters of Freundlich adsorption isotherm were summarized in Table 2. However, from all these parameters, it was concluded that the Langmuir adsorption model was well fitted than the Freundlich adsorption model to the adsorption of $\mathrm{MB}$ and aniline on the surface of sorbent (1:1:2) which confirms homogeneous and monolayer adsorption.

\section{Adsorption kinetics}

The experiments of adsorption kinetics of $\mathrm{MB}$ and aniline on the surface of sorbent (1:1:2) were carried out at room temperature and the data well fitted to the pseudo-second order kinetic model (Zheng et al. 2008; Simin et al. 2013) which can be expressed as:

$$
q_{t}=\frac{k_{2} t q_{t}^{2}}{1+k_{2} t q_{e}}
$$

where $q_{t}\left(\mathrm{mg} \mathrm{g}^{-1}\right)$ is the amount of adsorbate adsorbed at time $t(\mathrm{~min}), q_{\mathrm{e}}\left(\mathrm{mg} \mathrm{g}^{-1}\right)$ is the equilibrium adsorption capacity of sorbent, and $k_{2}\left(\mathrm{~g} \mathrm{mg}^{-1} \mathrm{~min}\right)$ is the secondorder rate constant. To determine the values of $k_{2}$ and $q_{\mathrm{e}}$ from the linear form of pseudo-second order kinetic model was taken as:

$$
\frac{t}{q_{t}}=\frac{1}{k_{2} q_{\mathrm{e}}^{2}}+\frac{t}{q_{\mathrm{e}}}
$$

The values of $k_{2}$ and $q_{\mathrm{e}}$ calculated from slope and intercept values of linear plot of $t / q_{t}$ against $t$ (Fig. 7a, b) are summarized in Table 3.

\section{Conclusions}

In this paper, we report the green and novel synthesis of ZVIN by renewable and naturally occurring CG flower extract as both reducing and stabilizing agent. UV-vis absorption and FT-IR spectral data confirm that the polyphenols present in the flower extract are responsible for the formation of ZVIN. The crystallinity of assynthesized ZVIN is confirmed by XRD analysis. The SEM images give the average size of synthesized ZVIN as $50-90 \mathrm{~nm}$. We also report the preparation of low-cost, eco-friendly, and efficient sorbent using synthesized ZVIN, biomaterial, and chitosan for the abatement of
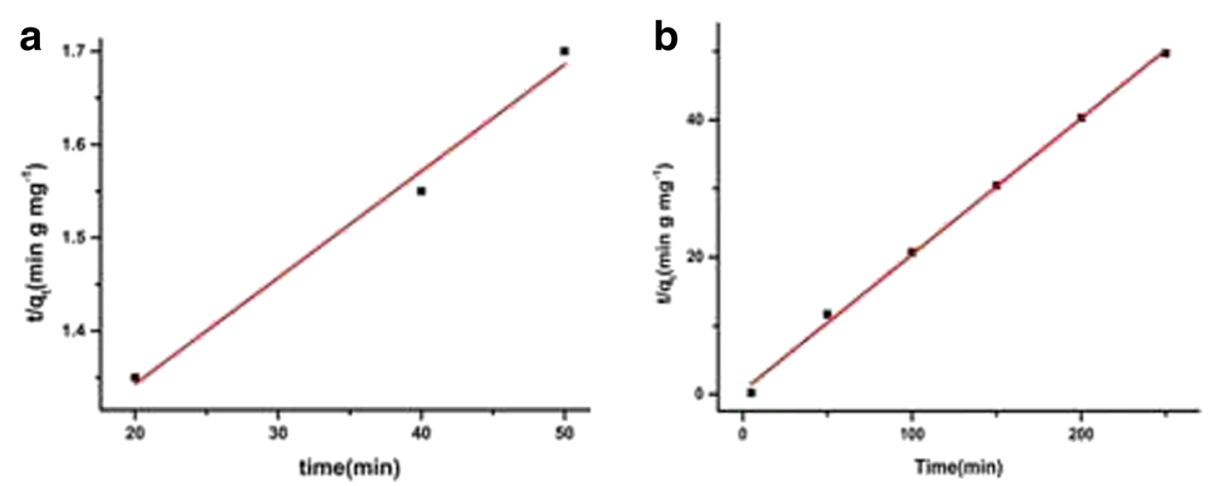

Fig. 7 (a, b) Pseudo-second order kinetic model for MB and aniline adsorption on sorbent (1:1:2) 
Table 3 Pseudo-second order parameters of adsorption data

\begin{tabular}{llll}
\hline & $q_{\mathrm{e}}(\mathrm{mg} / \mathrm{g})$ & $k_{2}\left(\mathrm{~g} \mathrm{mg}^{-1} \mathrm{~min}\right)$ & $R^{2}$ \\
\hline $\mathrm{MB}$ & 90.9 & $1 \times 10^{-4}$ & 0.94 \\
Aniline & 5.05 & 0.076 & 0.98 \\
\hline
\end{tabular}

aggregation of synthesized ZVIN. Here, the FT-IR analysis of synthesized sorbent reveals the immaculate support of biomaterial to ZVIN in the preparation of sorbent. The SEM analysis showed that ZVIN are well dispersed on the surface of the sorbent. ZVIN immobilized on biomaterial act as an efficient sorbent for the adsorption of water contaminants $\mathrm{MB}$ and aniline. Langmuir adsorption model was a well fit to the adsorption of MB and aniline on the surface of sorbent than the Freundlich model, and the adsorption process follows pseudo-second order kinetics.

\section{Abbreviations}

CG: Calotropis gigantea; EDX: Energy-dispersive X-ray spectroscopy; FTIR: Fourier transform infrared; MB: Methylene blue; SEM: Scanning electron microscope; UV-vis: Ultra-violet visible; XRD: X-ray diffraction; ZVIN: Zero-valent iron nanoparticles

\section{Acknowledgements}

The authors are thankful to the Head of the Department of Chemistry, Osmania University, for providing necessary facilities.

\section{Authors' contributions}

This work was designed by KS, DA, and PYS. The experimental work and analysis of the results were done by KS, DA, and PYS. This manuscript was written by KS, DA, and PYS. All authors read and approved the final manuscript.

\section{Competing interests}

The authors declare that they have no competing interests.

\section{Publisher's Note}

Springer Nature remains neutral with regard to jurisdictional claims in published maps and institutional affiliations.

Received: 29 June 2017 Accepted: 26 December 2017

Published online: 17 January 2018

\section{References}

Allabaksh MB, Mandal BK, Kesarla MK, Kumar KS, Reddy PS. Preparation of stable zero valent iron nanoparticles using different chelating agents. J Chem Pharm Res. 2010;2:67-74.

Arshadi M, Soleymanzadeh M, Salvacion JWL, Salimi VF. Nano scale zero-valent iron (NZVI) supported on sineguelas waste for $\mathrm{Pb}(\mathrm{II})$ removal from aqueous solution: kinetics, thermodynamic and mechanism. J Colloid Interface Sci. 2014;426:241-51.

Basavaraju S, Balaji DS, Mahesh DB, Ragunandan D, Prithviraj SPM, Venkataraman A. Solvothermal synthesis and characterization of acicular a$\mathrm{Fe}_{2} \mathrm{O}_{3}$ nanoparticles. Bull Mater Sci. 2011;34:1313-7.

Chicgoua N, Sabine C, Richard C. Nanoscale metallic iron for environmental remediation: prospects and limitations. Water Air Soil Pollut. 2012;223:1363-82.

Dey S, Bhattacharjee S, Bose RS, Ghosh CK. Room temperature synthesis of hydrated nickel (III) oxide and study of its effect on $\mathrm{Cr}(\mathrm{VI})$ ions removal and bacterial culture. Appl Phys A Mater Sci Process. 2015;119:1343-54.

Eastoe J, Dalton JS. Dynamic surface tension and adsorption mechanisms of surfactants at the air-water interface. Adv Colloid Interf Sci. 2000;85:103-44.

Fazlzadeh M, Rahmani K, Zarei A, Abdoallahzadeh H, Nasiri F, Khosravi R. A novel green synthesis of zero valent iron nanoparticles (NZVI) using three plant extracts and their efficient application for removal of $\mathrm{Cr}(\mathrm{VI})$ from aqueous solutions. Adv Powder Technol. 2017;28:122-30.
He F, Zhao D, Extended abstract and presentation, in: 230th ACS National Meeting, 28 August-1 September, Washington, DC, 2005.

Karimi EZ, Vahdati KJ, Zebarjad SM, Bataev IA, Bannovm AG. A novel method for fabrication of Fe catalyst used for the synthesis of carbon nanotubes. Bull Mater Sci. 2014;37:1031-8.

Khasim S, Raghavedra SC, Revanasiddappa M, Sajjan KC, Mohanalakshmi, Faisal Md. Characterization and magnetic properties of polyaniline. Bull Mater Sci 2011;34:1557-1561.

Kim JH, Tratnyek PG, Chang YS. Rapid dechlorination of polychlorinated dibenzo-p-dioxins by bimetallic and nanosized zerovalent iron. Environ Sci Technol. 2008;42:4106-12.

Kumar SP, Pooja G, Kaliaperumal S. Synthesis of a green nano iron particles (GnIP) and their application in adsorptive removal of $\mathrm{As}(\mathrm{III})$ and $\mathrm{As}(\mathrm{V})$ from aqueous solution. Appl Surf Sci. 2014;317:1052-9.

Lanlan H, Xiulan W, Zuliang C, Mallavarapu M. Green synthesis of iron nanoparticles by various tea extracts: comparative study of the reactivity. Spectrochim Acta A Mol Biomol Spectrosc. 2014;130:295-301.

Li X, Elliott DW, Zhang W. Zero-valent iron nanoparticles for abatement of environmental pollutants: materials and engineering aspects. Crit Rev Solid State Mater Sci. 2006;31:111-22.

Li XQ, Zhang WX. Iron nanoparticles: the core-shell structure and unique properties for Ni(II) sequestration. Langmuir. 2006;22:4638-42.

Nadagouda MN, Castle AB, Murdock RC, Hussain SM, Varma RS. In vitro biocompatibility of nanoscale zerovalent iron particles (NZVI) synthesized using tea polyphenols. Green Chem. 2010;12:114-22.

Machado S, Stawinski W, Slonina P, Pinto AR, Grosso JP, Nouws HPA, Albergaria JT, Delerue-Matosa C. Application of green zero-valent iron nanoparticles to the remediation of soils contaminated with ibuprofen. Sci Total Environ. 2013;461-462:323-9.

Madhavi V, Prasasd TNVKV, Vijaya BRA, Ravindra RB, Madhavi G. Application of phytogenic zerovalent iron nanoparticles in the adsorption of hexavalent chromium. Spectrochim Acta A Mol Biomol Spectrosc. 2013;116:17-25.

Madhavi V, Ravindra RB, Madhavi G, Prasad TNVKV, Vijay BRA. Conjunctive effect of CMC-zero-valent iron nanoparticles and FYM in the remediation of chromium-contaminated soils. Appl Nanosci. 2014;4:477-84.

Mehdi F, Kourosh R, Ahmad Z, Hossein A, Fakhraddin N, Rasoul K. A novel green synthesis of zero valent iron nanoparticles (NZVI) using three plant extracts and their efficient application for removal of $\mathrm{Cr}(\mathrm{VI})$ from aqueous solutions. Adv Powder Technol. 2017;28:122-30.

Mikhak A, K Md Z, Sohrabi A, Feizian M. Nano Fe(OH) 3 /Zeolite as a novel, green and recyclable adsorbent for efficient removal of toxic phosphate from water. Indian J Chem Technol. 2017;24:284-93.

Morales MA, de Souza Rodrigues EC, de Amorim ASCM, Soares JM, Galembeck F. Size selected synthesis of magnetite nanoparticles in chitosan matrix. Appl Surf Sci. 2013;275:71-4.

Mystrioti, Xenidis A, Sparis D, Dermatas D, Papasiopi N, Chrysochoou M. Assessment of polyphenol coated nano zero valent iron for hexavalent chromium removal from contaminated waters. Bull Environ Contam Toxicol. 2015;94:302-7

Qiangu Y, Caixia W, Jian L, Jinsen G, Fei Y, Jilei Z, Zhiyong C. Iron nanoparticles in situ encapsulated in biochar based carbon as an effective catalyst for the conversion of biomass-derived syngas to liquid hydrocarbons. Green Chem. 2013;15:1631-40.

Raveendran P, Fu J, Wallen SL. Completely "green" synthesis and stabilization of metal nanoparticles. J Am Chem Soc. 2003;125:13940-1.

Rebitanim NZ, Ghani WW, Mahmoud DK, Rebitanim NA, Salleh MM. Adsorption of methylene blue by agricultural solid waste of pyrolyzed EFB biochar. J Purity Util React Environ. 2012;1:346-60.

Richard A, Crane TS. The removal of uranium onto carbon-supported nanoscale zero-valent iron particles. J Nanopart Res. 2014;16:2813.

Ritu S, Virendra M, Rana PS. Synthesis, characterization and role of zero-valent iron nanoparticle in removal of hexavalent chromium from chromium-spiked soil. J Nanopart Res. 2011;13:4063-73.

Satapanajaru T, Anurakpongsatorn P, Pengthamkeerati P, Boparai H. Remediation of atrazine-contaminated soil and water by nano zero valent iron. Water Air Soil Pollut. 2008;192:349-59.

Shu HY, Chang MC, Chen CC, Chen PE. Using resin supported nano zero-valent iron particles for decoloration of acid blue 113 azo dye solutions. J Hazard Mater. 2010;184:499-505.

Shukla AK, Iravani S. Metallic nanoparticles: green synthesis and spectroscopic characterization. Environ Chem Lett. 2017;15:223-31. 
Simin A, Mahmoud RS, Morteza K. Adsorption kinetics and thermodynamics of vat dye onto zero-valent iron. Indian J Chem Technol. 2013;20:173-9.

Soon UY, Hun MH, Biswanath M, Chang GK. Phenol adsorption on surface-functionalized iron oxide nanoparticles: modeling of the kinetics, isotherm and mechanism. J Nanopart Res. 2016;18:170-9.

Sttle, Ttngo, Khanitchaidecha W, Nakaruk A. Synthesis of iron/GAC catalyst for wastewater treatment using heterogeneous Fenton reaction. Bull Mater Sci. 2015;38:1039-42.

Sunkara B, Zhan JJ, He JB, McPherson GL, Piringer G, John VT. Nanoscale zerovalent iron supported on uniform carbon microspheres for the in situ remediation of chlorinated hydrocarbons. ACS Appl Mater Interfaces. 2010;2: 2854-62.

Vazquez I, Rodriguez-Iglesias J, Maranon E, Castrillon L, Alvarez M. Removal of residual phenols from coke wastewater by adsorption. J Hazard Mater. 2007; 147:395-400.

Wang T, Jin X, Chen Z, Megharaj M, Naidu R. Green synthesis of Fe nanoparticles using eucalyptus leaf extracts for treatment of eutrophic wastewater. Sci Total Environ. 2014a;210:466-7.

Wang T, Lin J, Chen Z, Megharaj M, Naidub R. Green synthesized iron nanoparticles by green tea and eucalyptus leaves extracts used for removal of nitrate in aqueous solution. J Clean Prod. 2014b;83:413-9.

Wanyonyi WC, Onyari JM, Shiundu PM. Adsorption of Congo red dye from aqueous solutions using roots of Eichhornia crassipes: kinetic and equilibrium studies. Energy Procedia. 2014;50:862-9.

Yan W, Ramos MAV, Koel BE, Zhang WX. As(III) sequestration by iron nanoparticles: study of solid-phase redox transformations with X-ray photoelectron spectroscopy. J Phys Chem C. 2012;116:5303-11.

Zhang $E$, Wang $G$, Long X, Wang Z. Synthesis and influence of alkaline concentration on $a-\mathrm{FeOOH}$ nanorods shapes. Bull Mater Sci. 2014;37:761-5.

Zheng XC, Xiao YJ, Zuliang C, Mallavarapu M, Ravendra N. Removal of methyl orange from aqueous solution using bentonite-supported nanoscale zerovalent iron. J Colloid Interface Sci. 2011;363:601-7.

Zhipan W, Yalei Z, Chaomeng D. Removal of phosphate from aqueous solution using nanoscale zero valent iron (nZVI). Colloids and Surfaces colloids and Surfaces A: Physicochem Eng Aspects. 2014;457:433-40.

Zhou Y, Gao B, Zimmerman A, Fang J, Sun Y, Cao X. Sorption of heavy metals on chitosan-modified biochars and its biological effects. Chem Eng J. 2013;231:512-8.

Zheng $\mathrm{H}$, Wang $\mathrm{Y}$, Zheng $\mathrm{Y}$, Liang S, Long M. Equilibrium kinetics and thermodynamic studies on the sorption of 4-hydroxyphenol on Cr-bentonite. Chem Eng J. 2008;143:117-23.

\section{Submit your manuscript to a SpringerOpen ${ }^{\circ}$ journal and benefit from:}

- Convenient online submission

- Rigorous peer review

- Open access: articles freely available online

- High visibility within the field

- Retaining the copyright to your article

Submit your next manuscript at $\boldsymbol{\nabla}$ springeropen.com 